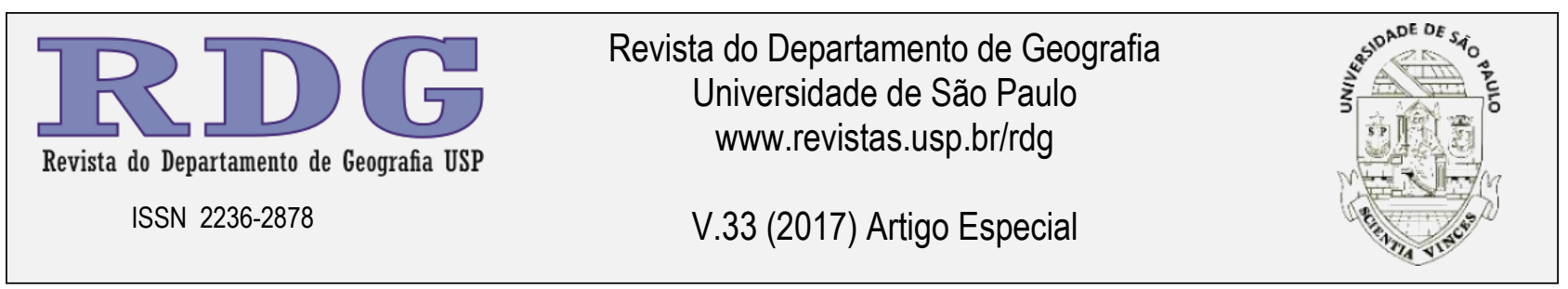

\title{
Trajetória Acadêmica Científica de José Pereira de Queiroz Neto*
}

\author{
Scientific Academic Trajectory of José Pereira De Queiroz Neto
}

Archimedes Perez Filho

Universidade Estadual de Campinas

archi@ige.unicamp.br

Resumo: Possui graduação em Agronomia pela Escola Superior de Agricultura Luiz de Queiroz. Universidade de São Paulo (1952); graduação em Química Agrícola - Universidade de Rennes I (1956); especialização em Geologia e Pedologia pela Escola Nacional Superior de Agronomia de Rennes (1955 - 1956, 800h); especialização em Pedologia Tropical pela ORSTOM (França) (1956 - 1958, 1760h); especialização em Estudos de Meio Natural da América Latina (1961 - 1962, 800h) na Universidade de Paris 1, SORBONE, França. Doutorado em Ciência do Solo pela ESALQ (USP) (1969), cuja tese versou sobre "Interpretação dos Solos da Serra de Santana para fins de Classificação" tendo como orientador Guido Ranzani. Professor Emérito da Universidade de São Paulo.

Palavras-Chave: Pedologia Tropical, Formações Superficiais, Solos e Geomorfologia, Coberturas Pedológicas.

\begin{abstract}
He holds a degree in Agronomy from the Luiz de Queiroz Higher School of Agriculture. University of São Paulo (1952); degree in Agricultural Chemistry - University of Rennes I (1956); Specialization in Geology and Pedology by the National Superior School of Agronomy of Rennes (1955 - 1956, 800h); Specialization in Tropical Pedology from ORSTOM (France) (1956 1958, 1760h); specialization in Natural Environment Studies of Latin America (1961 - 1962, 800h) at the University of Paris 1, SORBONE, France. PhD in Soil Science at ESALQ (USP) (1969), whose thesis was on "Interpretation of Soils of Serra de Santana for Classification purposes", having as advisor Guido Ranzani. Emeritus teacher of the University of São Paulo.
\end{abstract}

Keywords: Tropical Pedology, Surface Formations, Soils and Geomorphology, Soil Coverages.

\footnotetext{
* Artigo convidado para publicação na RDG (sem avaliação de pares, conforme regras do periódico). O artigo é proveniente da palestra ministrada pelo autor no XVII Simpósio Brasileiro de Geografia Física Aplicada/I Congresso Nacional de Geografia Física ocorrido no período de 28 de Junho à 02 de julho de 2017, na cidade de Campinas/SP.
} 
Possui graduação em Agronomia pela Escola Superior de Agricultura Luiz de Queiroz. Universidade de São Paulo (1952); graduação em Química Agrícola - Universidade de Rennes I (1956); especialização em Geologia e Pedologia pela Escola Nacional Superior de Agronomia de Rennes (1955 - 1956, 800h); especialização em Pedologia Tropical pela ORSTOM (França) (1956 - 1958, 1760h); especialização em Estudos de Meio Natural da América Latina (1961 - 1962, 800h) na Universidade de Paris 1, SORBONE, França. Doutorado em Ciência do Solo pela ESALQ (USP) (1969), cuja tese versou sobre "Interpretação dos Solos da Serra de Santana para fins de Classificação" tendo como orientador Guido Ranzani.

Em seguida (1969 - 1970), realiza Pós-Doutorado como bolsista do Centro Nacional de Pesquisa Científica, CNRS (França). Sua Livre-Docência é realizada no Departamento de Geografia da Faculdade de Filosofia, Letras e Ciências Humanas - USP (1975) tendo como título - "Pedogênese no Planalto Atlântico: contribuição à interpretação paleogeográfica dos solos da Mantiqueira".

Foi Professor Visitante da Universidade de Caen, França e do Instituto de Edafologia de Madrid, Espanha e recebeu título de Professor Emérito pela Universidade de São Paulo. Suas atividades acadêmicasprofissionais estão voltadas com ênfase na Pedogênese, atuando principalmente em temas relacionados a solos, sistemas de transformação, análise estrutural e geomorfologia.

José Pereira de Queiroz Neto inicia suas atividades profissionais em 1952 junto a Companhia Melhoramentos Norte de Paraná, CMNP, Brasil, onde passa a executar serviços técnicos especializados na Divisão de Maringá, setor de Agronomia. Seus trabalhos aí desenvolvidos possuíam caráter técnicocientífico voltados a agropecuária. Em 1958, vincula-se institucionalmente ao Instituto Agronômico de Campinas (IAC), mais precisamente na seção de Pedologia da Divisão de Solos, aí permanecendo por aproximadamente 10 anos, até 1967. Seus trabalhos versavam, sobretudo, a temas relacionados à Pedogênese, relações solos/geomorfologia e Física de solos. A partir de 1967, vincula-se ao Departamento de Geografia da Faculdade de Filosofia Letras e Ciências Humanas da Universidade de São Paulo.

Como Docente, José Pereira de Queiroz Neto teve intensa atuação tanto a nível de graduação como de Pós-Graduação no curso de Geografia do Departamento de Geografia da FFLCH - USP. Por mais de décadas ministrou, no ensino de Graduação, as disciplinas de Conservação dos Recursos Naturais; Pedologia; Fisiologia da Paisagem e Análise de Solos. Na Pós-Graduação, fortemente vinculada aos seus projetos de pesquisa, ministrou disciplinas denominadas de Formações Superficiais e Solos, Solos e Geomorfologia e Pedogênese e Relevo. Desta forma colaborou intensamente na formação de profissionais Geógrafos, em ambos os níveis.

A partir do seu ingresso no Departamento de Geografia, propõe a criação e desenvolvimento de uma linha de pesquisa, vinculadas às suas atividades principalmente na Pós-Graduação, denominada de "Relações entre Solos e Relevo". Linha esta que perdura até o momento atual. A partir de 1979 propõe a implantação de mais uma linha de pesquisa agora denominada de "Análise Estrutural das Coberturas Pedológicas". Importante mencionar que, no período de 1971 a 1979, tornou-se coordenador do convênio entre o Departamento de Geografia (FFLCH-USP) e o Centro de Geomorfologia CNRS-França), para o desenvolvimento da Cartografia geomorfológica, enfatizando as Formações Superficiais, Solos, Morfogênese, Quaternário, Terraços Fluviais e Depósitos correlatos. Neste mesmo período atua como Professor Colaborador na Universidade Federal da Bahia (UFBA), ministrando disciplina de Pós-Graduação denominada "Formações Superficiais, Solos e Geomorfologia".

Nas décadas seguinte, 80 e 90, além de suas atividades no Departamento de Geografia (FFLCH-USP) atua, também, como Professor Visitante na Universidade Federal do Mato Grosso do Sul (UFMS); ministra palestras, como convidado, pela Academia de Ciências do Estado de São Paulo, principalmente em escolas estaduais de ensino médio, sobre os temas: Erosão e seu controle; Pantanal - Patrimônio da Humanidade e O Cerrado Brasileiro. Programa extenso cujas atividades se realizaram até o final de 1992. Torna-se também, em 1991, Professor Visitante da Universidade Federal de Santa Catarina ministrando, na Pós-Graduação, a disciplina "Dinâmica do Meio Ambiente".

No período de 1978 a 1992, desenvolve atividades relacionadas à SBPC, destacando-se como membro assessor da diretoria em questões relacionadas ao meio ambiente. Fez também parte de comissões diversas, versando sobre estudos relacionados à Amazônia, Cubatão e Meio Ambiente.

De 1987 a 1998, mantém ligação junto ao Conselho Superior de Investigações Científicas (CSIC) Espanha, participando no projeto de pesquisa sobre Las Rañas, aplicando seus conhecimentos sobre "análise estrutural da cobertura pedológica" com o objetivo de compreender o comportamento hídrico dos solos, responsável pela dinâmica pedológica. 
Destaca-se no período de 1984 a 1992 o significativo relacionamento que manteve com instituições francesas, possibilitando intercâmbio intensamente frutífero ao Programa de Pós-Graduação em geografia Física do Departamento de Geografia da USP. Atua como Professor Visitante na Universidade de Caen (França), ministrando disciplinas na Graduação e Pós-Graduação, destacando-se "Dinâmica Ambiental em Marília - Estado de São Paulo" (O meio ambiente e sua dinâmica em Marília - Estado de São Paulo). Entretanto, é por meio do Centro Nacional de Pesquisas Científicas, CNPC - França, que Queiroz Neto mantém vínculo como coordenador do Projeto de Pesquisa intitulado "Relevo - Solo - Homem", desenvolvido em colaboração com Joel Pellerin. Passa, então, a desenvolver projetos de pesquisa junto à Divisão de Geografia, do Centro de Geomorfologia de Caen, relacionados à linha de pesquisa "Relevo Solo - Homem".

Marco histórico, a partir de seu ingresso no Departamento de Geografia - USP, que três grandes linhas de pesquisa tiveram seu desenvolvimento: $1^{\mathrm{a}}$. Relacionadas aos estudos das Formações Superficiais e da Cartografia Geomorfológica, na França e no Brasil; 2a. Relações entre solos e relevo, com o objetivo específico de estudar as relações entre as vertentes e os solos, principalmente no Brasil da SE. Inicia-se o emprego do procedimento: Análise Estrutural da Cobertura Pedológica.

Depreende-se de sua obra que a terceira linha "Análise estrutural das Coberturas Pedológicas", cujo objetivo se define como "Estudo das coberturas pedológicas brasileiras" onde (citado pelo autor) "O procedimento da análise estrutural não define o solo apenas pelo seu perfil vertical, mas sim como um corpo natural que recobre continuamente as vertentes, de alto a baixo. Assim, a cobertura pedológica tem três dimensões espaciais: comprimento (do alto da vertente até seu sopé), largura (que corresponde ao seu desenvolvimento lateralmente à linha de maior declive) e vertical (da superfície até a rocha sã). O estudo é realizado em diferentes escalas, desde a megamétrica até a micrométrica."

Ressalto que menciono apenas as principais linhas de pesquisa desenvolvidas pelo autor, quando do desenvolvimento de suas atividades acadêmicas junto ao Departamento de Geografia e ao Programa de PósGraduação em Geografia Física.

Com base nestas linhas de pesquisa, tomamos a liberdade de recorrer a duas obras (artigos), das muitas publicadas pelo homenageado, que acreditamos contemplar e refletir a brilhante trajetória acadêmica científica do mesmo.

O primeiro artigo que tomamos como referência, publicado pela Revista do Instituto Geológico, São Paulo, páginas 65-78, 2001, intitulado "O Estudo de Formações Superficiais no Brasil", onde o autor faz referência a duas grandes tendências, no Brasil, relacionadas ao estudo das formações superficiais. A visão pedológica, onde as formações representam os materiais de origem dos solos e a visão geomorfológica/geológica na qual as formações superficiais podem representar testemunhos dos processos responsáveis pela elaboração do relevo. O trabalho contribui com uma completa revisão sobre o estudo dos solos e as formações superficiais, assim como da Geomorfologia e as Formações Superficiais. Sobressaíram os estudos dos depósitos correlativos e os mapeamentos geomorfológicos de detalhe. Neste sentido o trabalho de Queiroz Neto (1969) "apresenta uma interpretação da gênese e evolução dos solos, relacionando suas características e propriedades, principalmente químicas, físico-químicas e mineralógicas à evolução do relevo. A presença de cascalheiras, linhas de pedra, blocos de couraça nas bordas de superfície de erosão plio-pleistocênicas fora interpretada como indicadora de descontinuidades litológicas e de superposições de materiais retrabalhados: assim, os materiais de origem dos solos seriam alóctones, desde os Latossolos de cimeira até os Podzólicos vermelho amarelo das vertentes e de níveis topográficos embutidos que apresentam, via de regra, stone-lines".

Entretanto, dúvidas permaneceram na interpretação, principalmente dos materiais que recobrem as vertentes. Queiroz Neto (1983) assinala que "um certo número de formas e formações superficiais foram interpretados com cautela, em virtude das dificuldades em definir os sistemas morfogenéticos responsáveis". "A interpretação morfogenética (dos colúvios) ainda não está bem definida". A seguir apesenta: "A nova contribuição da Pedologia ao Estudo das Formações Superficiais". Chega-se finalmente (na década de 70 pedólogos franceses trabalhando na África e Guiana Francesa) a um novo procedimento de estudo dos solos: "A análise estrutural da Cobertura Pedológica".

Em suas considerações finais, após balanço das tendências e mostrando os resultados alcançados, apresenta os procedimentos da análise da cobertura pedológica em duas direções:

$1^{\text {a }}$. possibilidade de uma definição mais correta da questão da autoctonia/aloctonia das formações superficiais, e 
$2^{a}$. avaliação e importância dos processos biogeodinâmicos na elaboração das formas do relevo.

A segunda obra tomada como referência, é o artigo publicado na Revista Brasileira de Geomorfologia, ano 1 no. 1, páginas 59 a 67, 2000, denominado Geomorfologia e Pedologia. Neste trabalho o autor faz excelente balanço entre as duas áreas de conhecimento afirmando, logo em sua introdução, que "apesar de lidarem com elementos naturais comuns, Geomorfologia e Pedologia trilharam caminhos diferentes por momentos tentativamente convergentes". As relações entre as diferentes áreas de conhecimentos só podem ser estabelecidas a partir do conhecimento das relações entre seus objetos de estudo, isto é, das relações entre os solos e os relevos. "Os caminhos diferentes percorridos pela Geomorfologia e pela Pedologia são, com certeza, o resultado de suas histórias".

Desta forma o autor nos conduz à evolução do pensar Geomorfológico e Pedológico sem, entretanto, deixar de incluir um vínculo com uma terceira área de conhecimento importante na análise das relações, ou seja, a Geologia. Apresenta a visão tradicional das relações entre os solos e superfícies de erosão terciárias e quaternárias. Conclui sua análise resumindo que as relações entre os solos e o relevo, no Brasil, foram interpretadas nas seguintes direções (do autor):

"1- através da posição ocupada pelos perfis na paisagem, relacionada à superfícies geomórficas de diferentes idades:

2- pela presença de diferenciações verticais no interior dos perfis de solo, interpretadas como descontinuidades erosivas, essas diferenciações poderiam ser marcadas pela presença de linhas de pedras e de horizontes escurecidos(enterrados);

3- pelo estabelecimento de cronossequências através dos resultados de análises laboratoriais e de interpretação da morfologia dos perfis;

4- pela presença de corpos ferruginosos (couraças - camadas concrecionárias) que denunciariam processos antigos de intemperismo."

Entretanto, o autor, ainda nesta obra, apresenta a contribuição dos estudos recentes de pedologia, fazendo referência à Análise Estrutural da Cobertura Pedológica, introduzida no Brasil no início da década de 1980. Esta nova visão viria a contribuir nas mudanças de pensamento até então vigentes, verticalista da Pedologia, que se baseia na análise de perfis isolados. A nova visão, permitiu introduzir a análise detalhada organização lateral/espacial da cobertura pedológica ao longo da vertente. Assim, torna-se possível demonstrar que a cobertura pedológica é contínua ao longo das vertentes e que as diferenciações registradas dizem respeito a sistemas de transformação lateral e não a perfis justapostos, como a visão anterior, obtida a partir de perfis verticais, levava a pensar.

Cuidadosamente nas Considerações Finais, Queiroz Neto destaca a necessidade de revisão de conceitos, direções e procedimentos de estudos nos estudos tradicionais das relações entre os solos e o relevo. Ressalta:

"1- A circulação interna das soluções do solo é um fator importante no modelado do relevo quanto a erosão superficial;

2- As coberturas pedológicas em equilíbrio dinâmico testemunham condições de menor atividade erosiva, enquanto sistemas de transformação lateral testemunham desequilíbrios hídricos nas vertentes;

3- A presença de stonelines e de horizontes sombrios enterrados podem ser apenas resultantes de atividades biológicas;

4- A gênese de corpos ferruginosos podem representar apenas uma etapa da alteração das rochas e formação dos solos, não sendo assim, testemunhas de ações paleo-climáticas."

Acreditando serem estas duas, entre suas inúmeras publicações, e s.m.j, reflexos de sua própria trajetória acadêmica científica, contribuiu e continuará contribuindo, de forma altamente significativa na formação de Geógrafos.

Encerro dizendo publicamente, Professor Queiroz Neto, receba esta homenagem com os mais sinceros agradecimentos em meu nome e da Comissão Organizadora do XVII Simpósio Brasileiro de Geografia Física Aplicada e do I Congresso Nacional de Geografia Física realizado no período de 28 de junho a 02 de julho de 2017 na Unicamp. 